\title{
NILAI MORAL DALAM CERITA BABAD CIREBON: BERDASARKAN PENCERITAAN DI KERATON KANOMAN
}

\author{
Nurhannah Widianti, Agus Nuryatin, dan Bambang Indiatmoko \\ Universitas Negeri Semarang, Indonesia \\ nurhannahw@gmail.com
}

\begin{abstract}
Abstrak
Babad Cirebon merupakan cerita legenda yang mengisahkan awal mula berdirinya Cirebon. Cerita tersebut diceritakan di Keraton Kanoman setiap 1 Muharam atau bertepatan dengan HUT Kota Cirebon. Hal itu dilakukan sebagai bentuk pelestarian karena cerita babad Cirebon berperan penting sebagai sarana penggugah nilai-nilai moral yang saat ini sangat dibutuhkan oleh masyarakat. Cerita ini dapat memberikan pelajaran mengenai berbagai nilai kebajikan. Hal itu dapat dibuktikan dari cerminan sikap yang ditunjukkan oleh Pangeran Walangsungsang sebagai pendiri Cirebon. Dari hasil analisis yang menggunakan pendekatan struktural, cerita babad Cirebon memuat 8 nilai moral, yakni nilai tanggung jawab, kejujuran, toleransi, penghormatan, kerja keras, kasih sayang, religius, dan tolong-menolong.
\end{abstract}

Kata kunci: cerita babad, nilai moral, tradisi lisan

\begin{abstract}
Babad Cirebon was a legend that told the beginning of the Cirebon establishment. The story was told in Kanoman every 1 Muharam or coincide on the Cirebon city anniversary. This was done as a preservation since the Babad Cirebon story was the crucial tool to appeal of moral values that today is needed by the local and society community in general. This story gave the lessons about the various virtues value. It can be proved from the reflection of the attitude that shown by Prince Walangsungsang as a founder of Cirebon. From the analysis used a structural approach, Babad Cirebon story that have been conveyed orally more than four decades contained 8 moral values such as the values of responsibility, honesty, tolerance, respect, hard work, compassion, religious, and mutual assistance.
\end{abstract}

Keywords: babad story, moral values, oral tradition

\section{A. Pendahuluan}

Sastra nusantara merupakan bagian dari kekhazanahan budaya yang dimiliki oleh bangsa Indonesia. Salah satu wujud dari sastra tersebut, yaitu cerita rakyat yang berperan penting sebagai sarana pengenalan dan penghayatan terhadap nilai-nilai moral. Salah satu cerita rakyat yang memuat nilai-nilai tersebut adalah cerita asal-usul Cirebon atau yang dikenal oleh masyarakat setempat dengan sebutan "Cerita Babad Cirebon”. Ditinjau dari segi jenis, babad Cirebon termasuk ke dalam cerita legenda karena pada intinya menceritakan asal-usul pendirian wilayah Cirebon. Kata babad memiliki makna merambah hutan, semak, atau belukar (Gunaevy, 2004). 


\section{Journal Indonesian Language Education and Literature Vol. 3, No. 1, Desember 2017 http://www.syekhnurjati.ac.id/jurnal/index.php/jeill/}

Isi cerita babad Cirebon mengisahkan pengembaraan Pangeran Walangsungsang (PW) yang ingin mempelajari agama Islam. Dalam perjalanannya itu, PW bertemu dengan para resi maupun syekh yang mengajarinya tentang hakikat dalam menjalani kehidupan dan hakikat beragama. Suatu hari, PW pun mendirikan pedukuhan atas perintah gurunya, yakni Syekh Datul Kahfii. Tempat itu kini dikenal dengan sebutan "Cirebon", yaitu suatu daerah yang terletak di ujung timur Ibu Kota Provinsi Jawa Barat dan berbatasan langsung dengan Brebes.

Dahulu tempat itu merupakan hutan belantara. PW merambahnya dengan bantuan 'Golok Cabang' yang bisa berbicara, mengeluarkan api, dan dapat mem-babad hutan dengan sendirinya. Cerita babad Cirebon memiliki unsur fantastis karena adanya hal-hal ajaib. Cerita babad Cirebon hingga saat ini tetap dilestarikan, khususnya oleh Keraton Kanoman melalui media penceritaan secara lisan. Upaya tersebut bertujuan untuk memberikan pengetahuan kepada masyarakat mengenai proses pendirian Cirebon dan sebagai sarana mengingatkan masyarakat terhadap jasa para leluhurnya. Cerita tersebut pun memuat nilai kepribadian, nilai sosial, maupun nilai kereligiusan.

Pangeran Rohim yang bergelar Pangeran Kumisi merupakan generasi keempat sebagai pencerita babad Cirebon. Sekitar tahun 1971-an, babad Cirebon telah disampaikan kepada masyarakat dengan cara dibacakan. Cerita yang dibacakan itu merupakan hasil nukilan. Dalam hal ini, adanya penggunaan suatu media pada acara tradisi lisan sangatlah wajar. Suatu cerita yang diwariskan secara lisan dan dikemas dalam tradisi biasanya disertai dengan alat bantu pengingat atau mnemonic device. Sarana itu berguna untuk membantu pencerita dalam mengungkapkan hal-hal yang harus disampaikannya kepada pendengar.

Hasil wawancara dengan Pangeran Rohim menunjukkan bahwa sampai saat ini tidak ada riwayat yang pasti tentang asal-muasal orang yang pertama kali menceritakan kisah tersebut. Pernyataan tersebut sangat relevan dengan pendapat Hutomo (1991) yang mengungkapkan bahwa folklor sebagai karya tradisional bersifat anonim. Tujuan utama digunakannya alat bantu itu agar masyarakat Cirebon di masa depan tidak kebingungan untuk mengetahui cerita asal-usul daerahnya. Realitas ini sekaligus menunjukkan bahwa penceritaan babad Cirebon yang diselenggarakan setiap satu tahun sekali itu atau bertepatan dengan peringatan HUT Kota Cirebon sangat penting untuk dijaga kelestariannya.

Penjelasan tersebut menegaskan pula bahwa cerita babad Cirebon merupakan bagian dari tradisi lisan karena penceritaannya selalu disajikan dalam acara tradisi untuk memperingati berdirinya Kota Cirebon. Hal itu diperkuat oleh Sibarani (2012) bahwa folklor yang memiliki latar peristiwa penceritaan sebagai konteks penggunaannya tergolong ke dalam tradisi lisan. 


\section{Journal Indonesian Language Education and Literature Vol. 3, No. 1, Desember 2017 \\ http://www.syekhnurjati.ac.id/jurnal/index.php/jeill/}

Ciri ini sangat penting untuk membedakan antara tradisi lisan dan folklor. Melalui penjelasan itu, maka penelitian ini tidak dapat dilepaskan dari keterkaitan antara cerita babad Cirebon dan proses penceritaannya.

Cerita babad Cirebon dan bentuk tradisinya memiliki peranan penting sebagai sarana untuk menggugah kembali nilai-nilai moral. Nilai moral adalah hal-hal kebaikan yang dibutuhkan dalam menjalani kehidupan. Nilai tersebut meminta dan menuntun agar segala sesuatu dilaksanakan dengan sebaik-baiknya (Lickona, 2012). Nilai moral meliputi nilai menghargai kehidupan dan kemerdekaan, tanggung jawab, kejujuran, keadilan, toleransi, penghormatan, disiplin diri, integritas, kasih sayang, dan dorongan untuk menjadi pribadi yang baik. Nilai moral tersebut sangat dibutuhkan oleh masyarakat Cirebon dan masyarakat pada umumnya. Misalnya tentang cara bersikap, bertoleransi, bertanggung jawab, saling menyayangi, dan tolong-menolong. Cerita tersebut sangat penting untuk dikenali dan dimaknai oleh masyarakat karena akan menghindarkan mereka dari demoralisasi, seperti melakukan kekerasan fisik maupun verbal, intoleransi, dan penyalahgunaan wewenang. Oleh karena itu, penelitian terhadap cerita babad Cirebon penting untuk dilakukan.

Adapun nilai-nilai moral yang terdapat dalam cerita legenda babad Cirebon dapat dikaji melalui karakter para tokohnya. Dalam hal ini, kajian difokuskan pada tokoh utama cerita, yaitu Pangeran Walangsungsang. Nurgiyantoro (2013) berpendapat bahwa tokoh merujuk pada pelaku, sedangkan penokohan berkenaan dengan penggambaran watak atau karakter seseorang tokoh yang dapat dilihat dari tiga segi, yakni dialog tokoh, penjelasan tokoh, dan penggambaran fisik tokoh.

Banyak nilai yang dapat diteladani dari cerita babad Cirebon. Salah satunya nilai tanggung jawab yang ditunjukkan oleh Pangeran Walangsungsang melalui sikapnya yang telah melaksanakan pembukaan lahan atas dasar perintah Syekh Datul kahfii. Namun sayangnya di era modern ini, khususnya generasi muda di Cirebon masih banyak yang belum mengetahui cerita asal-usul daerahnya. Hal itu dapat dibuktikan pada hasil penelitian awal. Hasil tersebut menunjukkan bahwa sebagian besar masyarakat Cirebon, khususnya generasi muda yang berusia 13-23 tahun tidak mengenali asal-usul daerahnya. Padahal, cerita babad Cirebon merupakan kekayaan budaya dan cerminan kehidupan masyarakat setempat yang menyimpan banyak hal tentang kebajikan.

Ketidaktahuan masyarakat tersebut berakibat tidak dikenalinya tokoh pendiri dan nilainilai yang terkandung di dalamnya. Fenomena tersebut mengidikasikan bahwa kepedulian masyarakat setempat terhadap cerita legenda daerahnya tergolong masih rendah. Kurang 


\section{Journal Indonesian Language Education and Literature Vol. 3, No. 1, Desember 2017 \\ http://www.syekhnurjati.ac.id/jurnal/index.php/jeill/}

kepedulian masyarakat Cirebon terhadap sastra dan budaya diperkuat oleh pernyataan Basyari (2016) dalam seminar nasional yang berjudul "Transformasi Nilai Sosial Budaya dalam Kurikulum dan Pembelajaran IPS.” Berbagai penelitian yang telah dilakukan menunjukkan bahwa kepedulian dan minat masyarakat terhadap budaya lokal Cirebon makin berkurang. Begitu pun dengan cerita babad Cirebon dan tradisi pembacaannya yang jarang sekali diketahui oleh masyarakat, khususnya kawula muda. Salah satu alasannya adalah karena bahasanya yang sulit dipahami. Keadaan ini diduga juga karena maraknya acara-acara di televisi yang mengusung tema modern dan arus modernisasi. Di sisi lain, orang tua, guru, dan sekolah pun kurang mengenalkan cerita dan budaya lokal kepada generasi muda.

Berdasarkan penjelasan di atas, maka dikhawatirkan cerita babad Cirebon bisa saja terlupakan oleh masyarakat pemiliknya. Kondisi itu turut diperparah dengan belum terdaftarnya babad Cirebon dan tradisi pembacaannya sebagai warisan budaya tak bendawi atau dalam konvensi Unesco disebut dengan Intangible Cultural Heritaaitadge (Sunarti 2015). Jika cerita tersebut tidak kunjung diapresiasi dengan baik, tentu akan membuat masyarakat setempat semakin asing terhadap cerita daerahnya sendiri. Hal ini tentu akan sangat disayangkan karena cerita babad Cirebon dapat merefleksikan kehidupan masyarakat yang majemuk dan secara nyata dapat menjadi contoh hidup bermasyarakat yang beradab serta bermartabat.

\section{B. Metode Penelitian}

Penelitian merupakan suatu tindakan ilmiah yang dilakukan terhadap suatu bidang ilmu berlandaskan prosedur ilmiah yang telah ditetapkan. Cerita babad Cirebon yang diceritakan oleh Pangeran Rohim atau Pangeran Kumisi di Keraton Kanoman pada Senin, 3 Oktober 2016 dikaji menggunakan pendekatan struktural. Pendekatan ini menitikberatkan pembahasan dari sisi cerita babad Cirebon saja. Artinya, unsur luar yang memengaruhi adanya cerita tersebut diabaikan. Teori menurut Lickona digunakan sebagai acuan untuk mengungkap nilai moral yang termuat dalam cerita babad Cirebon.

Analisis data diawali dengan melakukan transkripsi dari bentuk lisan ke bentuk tulis. Lalu, cerita tersebut dialihbahasakan dari bahasa Cirebon ke bahasa Indonesia. Hal ini dilakukan untuk mempermudah proses analisis. Analisis ini juga diperkuat dengan adanya pencantuman penggalan cerita yang menunjukkan nilai moral. Pengkajian nilai moral dalam cerita babad Cirebon didasarkan pada pencatatan hal-hal yang tampak atau tersirat dalam cerita tersebut. 


\section{Journal Indonesian Language Education and Literature Vol. 3, No. 1, Desember 2017}

http://www.syekhnurjati.ac.id/jurnal/index.php/jeill/

\section{Hasil dan Pembahasan}

Nilai-nilai moral dalam cerita babad Cirebon dapat ditinjau dari beberapa tokoh pada cerita. Setiap tokoh membawa pesan-pesan yang dapat dijadikan teladan. Penelitian ini berfokus pada tokoh Pangeran Walangsungsang saja. Nilai moral dalam cerita babad Cirebon, meliputi: nilai tanggung jawab, kejujuran, toleransi, penghormatan, kerja keras, kasih sayang, religius, syukur, dan tolong-menolong. Berikut ini analisisnya.

Tanggung Jawab. Nilai tanggung jawab dalam cerita babad Cirebon tercermin dari pemenuhan komitmen yang telah disepakati antara Pangeran Walangsungsang dan gurunya. Bahkan, Sang Pangeran bersedia menerima apa pun konsekuensi dari tindakan yang dilakukannya. Hal tersebut ditunjukkan Sang Pangeran saat berusaha memenuhi tugas dari Syekh Datul Kahfi untuk melakukan pembabadan hutan yang akan difungsikan sebagai pemukiman.

(1) “...Saya sudah yakin kamulah yang akan menerima giliran membuat negara. Mulailah! Babadlah hutan yang berada di selatan Gunung Jati!”

Pangeran mengucapkan ke-siapannya, "Dengan izin Kyai, saya diberi perintah masuk ke dalam api kematian pun saya laksanakan."

Lalu, Pangeran membabat hutan dengan menghunuskan "Golok Cabang”. Golok itu berpamitan kepada Pangeran Walang-sungsang untuk membabat hutan yang luas secara pribadi. Kayu pun roboh karena golok. Lalu, keluarlah api dan hutan itu habis terbakar tanpa kayu. Hutan berubah menjadi terang, beberapa meter persegi digunakan untuk dibangun pondok yang disebut dengan "Witana". Witana yang nantinya dibangun sebagai Keraton Kanoman tempat orang yang berkarya.

Dalam penggalan tersebut tampak jelas bahwa Sang pangeran melaksanakan perintah dari gurunya untuk membabad hutan. Di sinilah akhirnya pada 1 Sura tahun Saka 1302 atau 1 Muharam tahun Hijriyah 791 Pangeran Walangsungsang mendirikan Cirebon.

Kejujuran. Kejujuran merupakan sikap seseorang untuk tidak berbohong kepada orang lain sehingga tidak membuat orang lain merasa tertipu. Nilai kejujuran dalam cerita babad Cirebon digambarkan oleh tokoh Pangeran Walangsungsang yang men-jawab pertanyaanpertanyaan sesuai dengan fakta atau apa adanya. Sikap jujur pangeran ditunjukkan ketika ia menolak tawaran menjadi Raja Padjajaran karena terlebih dahulu ingin mempelajari agama Islam. Pangeran Walangsungsang mengungkapkan hal tersebut atas dasar mimpi dan orang yang berbicara kepadanya tanpa rupa. Walangsungsang tidak mencoba menutupi hal yang dialaminya, meski pada akhirnya ia harus menerima bahwa Prabu Siliwangi sangat marah dan mengusirnya dari keraton. 


\section{Journal Indonesian Language Education and Literature Vol. 3, No. 1, Desember 2017 http://www.syekhnurjati.ac.id/jurnal/index.php/jeill/}

(2) "Duhai putraku Walangsungsang, jadilah Engkau raja menguasai negara dengan adikmu", kata Sang Prabu.

"Ya Ramanda, putranda mohon perkenanan Paduka. Sebelum hamba bertemu dengan orang yang terbayang dalam mimpi, soal tahta hamba kesampingkan", ujar Walangsungsang.

"Oh, apakah impianmu gerangan?"

Pangeran Walangsungsang men-jawab, "Putranda bertemu dengan Nabi Muhammad. Mohon Ramanda agar berguru agama kepadanya, berguru agama Nabi Rasulullah kepada seorang pandita di Gunung Amparan Jati. Jadilah orang muslim. Barang siapa tidak masuk Islam akan menjadi kufur dan masuk neraka.”

Toleransi. Nilai toleransi dalam cerita babad Cirebon ditunjukkan oleh sikap Pangeran Walangsungsang terhadap ayahnya. Sang Pangeran tetap menghargai pendapat, keyakinan, atau keputusan dari Prabu Siliwangi yang menolak menjadi muslim. Bahkan, Pangeran Walangsungsang tidak melakukan kekerasan fisik maupun verbal saat Sang Prabu Siliwangi mengusirnya apabila tetap ingin belajar agama Islam. Hal ini menunjukkan bahwa Pangeran Walangsungsang tidak memaksakan kehendaknya terhadap orang lain.

(3) Pangeran Walangsungsang menjawab, "Putranda bertemu dengan Nabi Muhammad. Mohon Ramanda agar berguru agama kepadanya, berguru agama Nabi Rasulullah kepada seorang pandita di Gunung Amparan Jati. Jadilah orang muslim. Barang siapa tidak masuk Islam akan menjadi kufur dan masuk neraka." Prabu Siliwangi membentak, "Buat apa berguru Islam?

Kita punya agama sendiri, Walangsungsang! Bila engkau tidak menuruti perintahku, per-gilah dari keraton! Saya tidak sudi memiliki anak sepertimu! Patih Arga! Patih Arga umumkan ke seluruh negara dan perbatasan, barang siapa menerima kedatangan anakku Walangsungsang harus dihu-kum atau kau bunuh!"....

Pada hakikatnya setiap orang memiliki hak untuk menentukan pilihan sesuai dengan yang diyakininya termasuk perihal agama. Hal tersebut tercermin dari tindakan Pangeran Walangsungsang yang tidak memaksakan ayahandanya untuk mengikuti agama yang diyakininya, yaitu Islam. Dalam ajaran Islam seseorang tidak diperkenankan memaksakan orang lain agar memeluk agama Islam apabila bukan dari keinginan pribadi.

Kesantunan. Nilai kesantunan merupakan bentuk penghargaan terhadap orang lain tanpa melihat kedudukan, pangkat, serta asal orang tersebut. Nilai kesantunan dalam cerita babad Cirebon ditunjukkan oleh sikap dan perkataan Pangeran Walangsungsang pada penggalan berikut ini.

(4) Pangeran Walangsungsang mem-beri penghormatan dan berkata "Iya" Walangsungsang datang ke hadapan Sang Hyang Danuwarsih, sujud dan mencium tangan. 


\section{Journal Indonesian Language Education and Literature Vol. 3, No. 1, Desember 2017 http://www.syekhnurjati.ac.id/jurnal/index.php/jeill/}

(5) Pangeran berkata, "Terima kasih banyak. Saya sudah diberi nasihat tentang sejatinya hidup."

Kerja keras. Nilai kerja keras berkaitan dengan upaya seseorang dalam mencapai suatu tujuan dengan sungguh-sungguh. Hal tersebut ditunjukkan oleh Pangeran Walangsungsang melalui kegigihannya dalam mencari dan mempelajari agama Islam. Ia sangat sungguhsungguh belajar Islam. Ia rela pergi dari keraton dan meninggalkan segala haknya. Ia mengembara ke berbagai tempat hingga berguru ke Mekkah. Berkat kegigihannya itu pula ia dapat memahami seluruh kandungan Al-Quran sehingga ia dapat pulang ke tanah Jawa dengan ilmu agama Islam yang mempuni. Hal ini menjadi bekal untuk ia menyebarkan agama Islam di sana.

(6) Pangeran, kemudian pergi ke arah tenggara. Perjalanan itu ia lalui dengan kewaspadaan, menyamar, dan hati-hati hingga ia lupa tidur dan makan. Selanjutnya, ter-lihatlah nyala api di Gunung Merapi.

Kasih sayang. Nilai kasih sayang berhubungan dengan keharmonisan. Nilai kasih sayang berhubungan dengan sikap yang menunjukkan perasaan penuh kasih sayang dan bersikap penuh kelembutan sehingga ada keterjalinan rasa saling melindungi. Hal itu ditunjukkan Pangeran Walang-sungsang kepada Rarasantang (adiknya).

(7) Pangeran Walangsungsang segera memandang dengan teliti. Adik-nya langsung dipeluk, "Aduh, adikku siapa yang menemani ke sini?" Keduanya tanpa sungkan berpelukan, "Aduh saudaraku."

(8) Pangeran menyampaikan pesan kepada Rarasantang, "Pandai-pandailah menjaga diri dan janganlah Rarasantang me-mikirkan siang dan malam. Jadilah isteri yang tahu berbakti kepada suami."

Religius. Nilai religius mencerminkan tentang kepribadian seseorang yang memiliki keimanan. Dalam kata lain berkaitan juga dengan prinsip kehidupan. Hal ini ditunjukkan oleh Pangeran Walangsungsang yang teguh pada pendiriannya untuk tetap belajar dan memeluk agama Islam, meski ayahandanya tidak menghendaki keinginannya tersebut. Ia tetap berkeyakinan bahwa agama Nabi Muhammad adalah agama yang sejati. Hal ini mengajarkan agar seseorang tetap teguh pendirian, terutama tentang keimanan.

(9) Pangeran tidak lama kemudian pergi dari adiknya, "Saya berada pada jalan yang baik."

Tolong Menolong. Tolong menolong merupakan nilai yang menunjukkan kepekaan seseorang terhadap sesama tanpa memiliki motif untuk mendapatkan hadiah atau pujian. 


\section{Journal Indonesian Language Education and Literature Vol. 3, No. 1, Desember 2017 \\ http://www.syekhnurjati.ac.id/jurnal/index.php/jeill/}

Dalam cerita babad Cirebon, nilai tersebut ditunjukkan oleh Pangeran Walangsungsang saat menolong Sultan Aceh yang terkena wabah penyakit.

(10) Orang Jawa pun memaksa, "Hamba sanggup menyembuhkan penyakit Sang Gusti."...Syekh Abdul Iman mengeluarkan jampi, "Yang awalnya sehat menjadi sehat. Sultan jadilah sehat. Tidak mencari obat lagi."

\section{Simpulan}

Cerita babad Cirebon memuat delapan nilai moral, yakni tanggung jawab, kejujuran, toleransi, peng-hormatan, kerja keras, kasih sayang, religius, dan tolong-menolong. Nilai-nilai moral yang terdapat dalam cerita legenda babad Cirebon itu tercermin dari sikap yang ditunjukkan oleh Pangeran Walangsungsang. Berbagai nilai tersebut menunjukkan bahwa cerita babad Cirebon berperan sebagai sarana pengenalan dan penghayatan terhadap nilai-nilai kebajikan. Oleh karena itu, cerita babad Cirebon dan bentuk tradisinya perlu terus dilestarikan. Masyarakat seharusnya tidak lagi memiliki anggapan bahwa mengenali dan menghayati cerita tersebut merupakan sesuatu yang kuno. Hal itu malah bisa dimanfaatkan sebagai tolok ukur agar masyarakat pemilik cerita tersebut dapat menjalani kehidupan yang lebih baik dari para pendahulunya.

\section{Daftar Pustaka}

Basyari, Iin Wariin. (2016). "Transformasi Nilai Sosial Budaya dalam Kurikulum dan Pembelajaran IPS”. Makalah. Seminar Nasional Kearifan Lokal Daerah di Keraton Kasepuhan. Cirebon, 25 September 2016.

Gunaevy, Siti Joya Fatmi. (2004). Babad Tanah Jawi. Terjemahan Rochkyatmo, dkk. Jakarta: Amanah-Lontar.

Hutomo, Suripan Sadi. (1991). Mutiara yang Terlupakan: Pengantar Studi Sastra Lisan. Surabaya: Hiski.

Lickona, Thomas. (2012). Educating for Character (Mendidik untuk Membentuk Karakter). (Terj. Juma Abdu Wamaungo). Bandung: Bumi Aksara.

Nurgiyantoro, Burhan. (2013). Teori Pengkajian Fiksi. Gadjah Mada University Press: Yogyakarta.

Sibarani, Robert. (2012). Kearifan Lokal: Hakikat, Peran, dan Metode Tradisi Lisan. Jakarta: Asosiasi Tradisi Lisan.

Sunarti, Pudentia M. P. S. (2015). Tradisi Lisan dan Warisan Budaya. Jakarta: Asosiasi Tradisi Lisan. 